Case Report

\title{
A Case of 17q21.31 Microduplication and 7q31.33 Microdeletion, Associated with Developmental Delay, Microcephaly, and Mild Dysmorphic Features
}

\author{
Adrian Mc Cormack, ${ }^{1}$ Juliet Taylor, ${ }^{2}$ Leah Te Weehi, ${ }^{1}$ \\ Donald R. Love, ${ }^{1,3}$ and Alice M. George ${ }^{1}$ \\ ${ }^{1}$ Diagnostic Genetics, LabPlus, Auckland City Hospital, P.O. Box 110031, Auckland 1148, New Zealand \\ ${ }^{2}$ Genetic Health Service New Zealand-Northern Hub, Auckland City Hospital, Private Bag 92024, Auckland 1142, New Zealand \\ ${ }^{3}$ School of Biological Sciences, University of Auckland, Private Bag 92019, Auckland 1142, New Zealand \\ Correspondence should be addressed to Alice M. George; aliceg@adhb.govt.nz
}

Received 23 October 2013; Accepted 2 December 2013; Published 4 February 2014

Academic Editors: D. J. Bunyan, P. D. Cotter, A. DeWan, and S. Ennis

Copyright ( 2014 Adrian Mc Cormack et al. This is an open access article distributed under the Creative Commons Attribution License, which permits unrestricted use, distribution, and reproduction in any medium, provided the original work is properly cited.

Concurrent cryptic microdeletion and microduplication syndromes have recently started to reveal themselves with the advent of microarray technology. Analysis has shown that low-copy repeats (LCRs) have allowed chromosome regions throughout the genome to become hotspots for nonallelic homologous recombination to take place. Here, we report a case of a 7.5-year-old girl who manifests microcephaly, developmental delay, and mild dysmorphic features. Microarray analysis identified a microduplication in chromosome 17q21.31, which encompasses the CRHR1, MAPT, and KANSL1 genes, as well as a microdeletion in chromosome $7 \mathrm{q} 31.33$ that is localised within the GRM8 gene. To our knowledge this is one of only a few cases of $17 \mathrm{q} 21.31$ microduplication. The clinical phenotype of patients with this microduplication is milder than of those carrying the reciprocal microdeletions, and suggests that the lower incidence of the former compared to the latter may be due to underascertainment.

\section{Introduction}

Since the advent of microarray technology considerable progress has been made in identifying small scale chromosome imbalances. The existence of colocalized microdeletion and microduplication syndrome sites has come to the fore in the recent years and a significant number of new microduplication syndromes have emerged such as $17 \mathrm{p} 11.2$ [1] and 22q11.21 [2]. These syndromes, like the corresponding microdeletion syndromes at these locations, appear to be driven by nonallelic homologous recombination (NAHR) involving low-copy repeats (LCRs or segmental duplications) [3-8]. LCRs are DNA fragments greater than $1 \mathrm{~Kb}$ in size, have 90\% DNA sequence homology, and are thought to account for approximately $3-10 \%$ of the total genome.

The MAPT gene located on chromosome 17q21.31 is flanked by LCRs and two extended haplotypes, designated H1 and $\mathrm{H} 2$, have been identified $[9,10]$. The $\mathrm{H} 2$ haplotype is a $900 \mathrm{~kb}$ inversion polymorphism that has been reported as the likely ancestral state and which has a tendency to undergo recombination [11] leading to the $17 \mathrm{q} 21.31$ microdeletion syndrome. This syndrome has been well characterised and appears to be caused by haploinsufficiency of at least one gene, KANSL, within the deleted region $[12,13]$. The more common $\mathrm{H} 1$ haplotype appears to be overrepresented in patients manifesting progressive supranuclear palsy [14].

Here, we report a 7.5 -year-old girl with a $647 \mathrm{~kb}$ duplication involving interstitial chromosome region 17q21.31 as well as a $232 \mathrm{~kb}$ heterozygous interstitial deletion involving chromosome region 7q31.33. We review this case in conjunction with other 17q21.31 microduplication cases described by Kirchhoff et al. [15], Kitsiou-Tzeli et al. [16], and Grisart et al. [17]. Our case shares some common phenotypic features with previously reported patients, including developmental 
delay, microcephaly, and mild dysmorphisms, which are milder than those identified in patients with the 17q21.31 microdeletion syndrome.

\section{Clinical Report}

The proband was the first born girl to nonconsanguineous Iraqi and Afghani parents. Family history on the mother's side was unremarkable. The father reportedly struggled at school and it has been suggested that he may have been microcephalic. The child was delivered at 38-week gestation via induction as there were concerns about IUGR. She was born in good condition and did not require resuscitation. Birth weight was $2490 \mathrm{~g}$ ( 3 rd to 10th centile) and there were no other antenatal complications. Milestones were appropriate for age, walking at 15 months but always on her toes. She was initially referred to a child development service as she was falling a lot when walking and was prescribed orthoses. At the age of 2 years and 7 months she was further referred to a pediatric clinic because of her gait pattern. It was noted that she still had difficulty with toe walking, lack balance, and control when walking along slopes and stairs and was still learning how to do other developmental skills such as climbing, jumping, and pushing a bike. There were no obvious dysmorphic features. Her weight was $15.55 \mathrm{~kg}$ (90th centile), height was $92 \mathrm{~cm}$ (25th-50th centile), and head circumference was $46 \mathrm{~cm}$ (25th centile). A follow-up visit at 3 years of age showed that the idiopathic toe walking had resolved and that gross motor skills were continuing to develop. At the age of 5.5 years, she was found to be functioning at a level well below chronological age and was noted to be microcephalic (head circumference of $47 \mathrm{~cm}$; 2nd centile) as well as developmentally delayed. Dysmorphic features were not observed at this visit, but some mild autistic traits were seen.

Developmental delay was further confirmed 2 years later, functioning at 4-5-years old level both academically and for fine motor skills. She required significant assistance with activities of daily life. It was also noticed at this visit that she had some dysmorphic features with possible almond shaped eyes and small hands.

\section{Cytogenetic and Molecular Studies}

Genome-wide copy number analysis of the proband was undertaken using an Affymetrix CytoScan $750 \mathrm{~K}$ Array, according to the manufacturer's instructions. Regions of copy number change were determined using the Affymetrix Chromosome Analysis Suite software (ChAS) v.1.2.2 and interpreted with the aid of the UCSC genome browser (http://genome.ucsc.edu/; Human Feb. 2009 GRCh37/hg19 assembly). The array showed a female molecular karyotype with a $232 \mathrm{~kb}$ heterozygous interstitial deletion involving chromosome region 7q31.33 [hg19 coordinates chr7:126,531,039-126,763,294] and a $647 \mathrm{~kb}$ duplication involving interstitial chromosome region 17q21.31 [hg 19 coordinates chr17:43,645,879-44,292,742]. The 7q31.33 microdeletion contains part of one gene, GRM8 (OMIM
601116), while the 17q21.31 microduplication contains a number of genes including CRHR1 (OMIM 122561), IMP5 (SPPL2C; OMIM 608284), MAPT (OMIM 157140), and STH (OMIM 607067) and a partial duplication of the KANSL1 gene (also known as KIAA1267, OMIM 612452); see Figure 1.

In order to determine the genotype encompassing the $M A P T$ gene, we focused on amplifying the region of intron 9 of the MAPT gene that carries a polymorphic 238 bp deletion, which is a characteristic marker of the $\mathrm{H} 1 / \mathrm{H} 2$ genotypes. Fifty nanograms of genomic DNA was subjected to PCR amplification using Roche FastStart buffer (without $\mathrm{Mg}$ ), $1.5 \mathrm{mM}$ $\mathrm{MgCl}_{2}, 0.4 \mathrm{mM}$ dNTPs, 1 unit Roche Faststart Taq DNA polymerase, and $0.8 \mu \mathrm{M}$ of each forward and reverse primer [14]. PCR cycle conditions comprised $95^{\circ} \mathrm{C}$ for 5 minutes and then 35 cycles of $94^{\circ} \mathrm{C}$ for 30 seconds, $55^{\circ} \mathrm{C}$ for 30 seconds, and $72^{\circ} \mathrm{C}$ for 30 seconds, with a final extension at $72^{\circ} \mathrm{C}$ for 10 minutes. Amplified DNAs were electrophoretically separated in a $2 \%$ E-gel (Life Technologies) and the amplicons visualised under UV light. Only the $246 \mathrm{bp}$ fragment was detected, suggesting the $\mathrm{H} 2$ genotype, hence an $\mathrm{H} 2 / \mathrm{H} 2 / \mathrm{H} 2$ haplotype.

\section{Discussion}

From the literature review, six cases of 17q21.31 microduplication syndrome have been previously reported [15-17]. Our patient together with two others also had an additional CNV. Kitsiou-Tzeli et al. [16] reported an additional $413 \mathrm{~kb} 15 \mathrm{q} 11.2$ deletion, and these authors have stated that this deletion may have contributed to some of the phenotypic symptoms of their patient. Patient 3 reported by Grisart et al. [17] had the common 17p11.2 deletion but was asymptomatic for NHPP (OMIM 162500) associated with this anomaly.

Molecular characterisation of our patient showed two abnormalities. In the case of the 7q31.33 microdeletion, the pathological significance of a partial deletion of the GRM8 gene in this region has not been determined. The GRM8 gene encodes a neurotransmitter receptor that responds to glutamate stimulation [18]. A partial duplication of the GRM8 gene has been discovered in an individual with autistic spectrum disorder [19]. Further studies have indicated that deletions in this gene may be over-represented in some patients with ADHD [20]. While our patient does show some traits of autism, she has excellent social skills so she has not been further investigated for this condition. Therefore, we are uncertain if this partial deletion of the GRM8 gene has a significant effect on the phenotype of our patient.

The duplicated region of 17q21.31 contains a small number of genes (Figure 1). Some are linked to a specific phenotype such as the MAPT gene (microtubule associated protein $T A U)$. This gene encodes proteins that stabilise microtubules, which are mostly found in neurons. Loss of function abnormalities of this gene is associated with neurodegenerative disorders such as frontotemporal dementia with Parkinson's disease, progressive supranuclear palsy, and Alzheimer's disease $[21,22]$. Interestingly, these disorders have also been reported to be associated with over-expression of other genes such as $\alpha$ synuclein gene in some cases of Parkinson's disease 


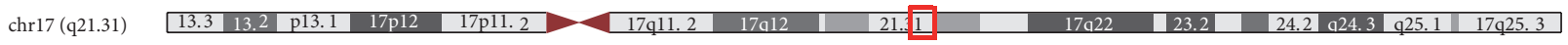

(a)

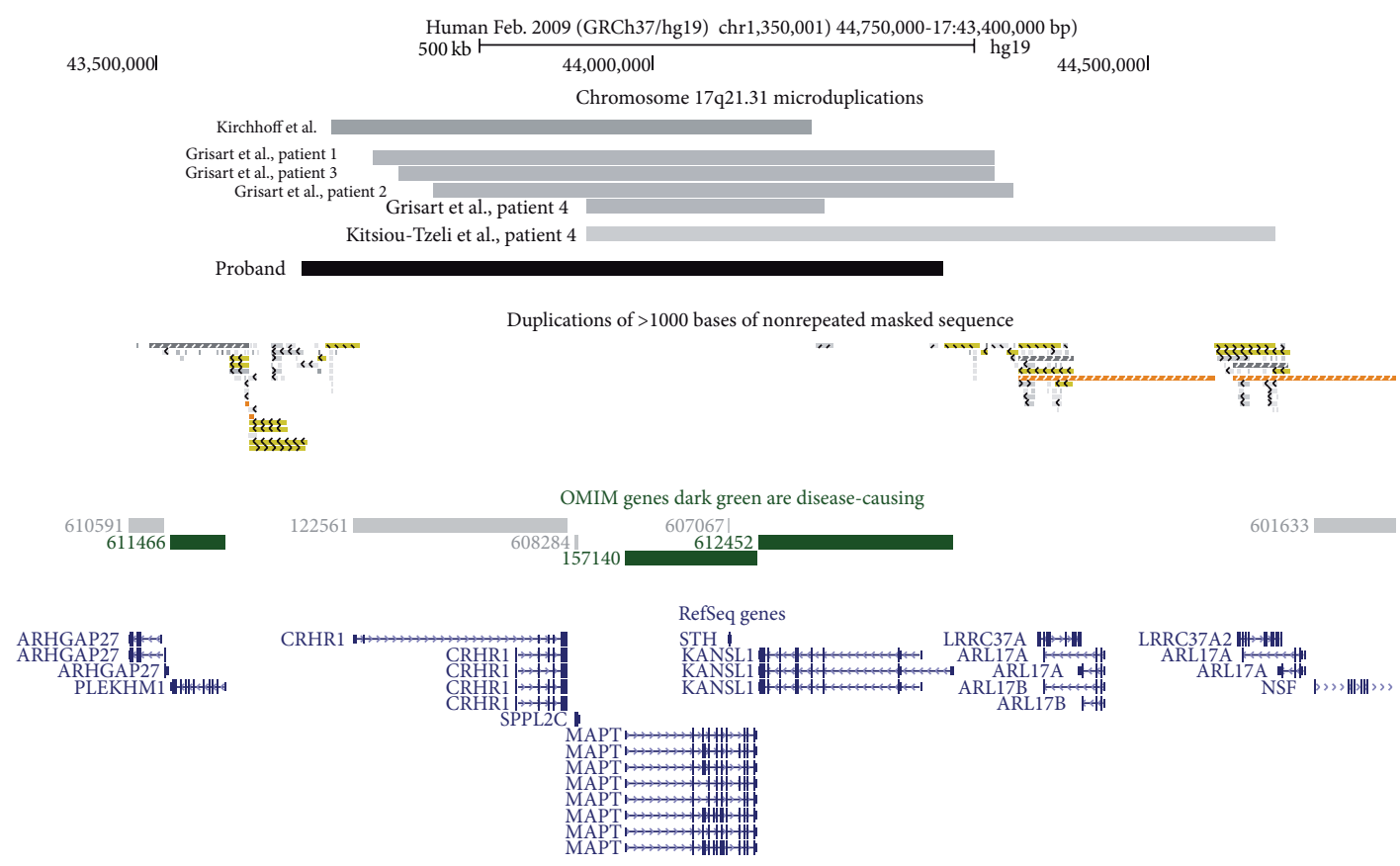

(b)

FIGURE 1: Schematic of the chromosome 17 region containing the microduplication. Panel A shows an ideogram of chromosome 17, together with the region encompassing the microduplications. Panel B shows the location and extent of the duplications detected in the proband reported here, other cases reported in the literature, LCRs (segmental duplications), and OMIM and Refseq genes that lie within the microduplicated region. These graphics were taken from the UCSC genome browser (http://genome.ucsc.edu/).

and amyloid precursor protein (APP gene) in Alzheimer's disease $[23,24]$.

Mouse models have shown that over-expression of the murine homologue of the TAU gene models the impact of human $\mathrm{H} 1 / \mathrm{H} 1$ MAPT haplotype, increasing the expression of the tau protein and thereby the risk of the development of associated tauopathies [25]. However, larger screening of the $M A P T$ gene has shown that copy number gains have not so far been implicated in neurodegenerative diseases [26].

The CRHR1 gene encodes a corticotrophin releasing hormone receptor type 1 and is involved in coordinating the endocrine, autonomic, behavioural, and immune responses to stress through actions in the brain and the periphery [27]. Polymorphisms in this gene have commonly been associated with depression and panic disorder $[28,29]$. The IMP5 gene encodes intramembrane protease 5 , which is a part of a class of enzymes which cleave integral membrane proteins [30]. The KANSL1 gene encodes a nuclear protein which plays a role in chromatin modification. It encodes two subunits which play a role in a histone acetyltransferase complex [31]. Finally, the STH gene is a polymorphic gene nested within an intron of the MAPT gene and encodes the protein Saitohin [32], the function of which is not yet known.

Table 1 summarises the clinical phenotypes of the limited number of 17q21.31 microduplication cases reported thus far.
In most cases pregnancies tend to be very uneventful (5/7) and early milestones normal (7/7). One of the first main signs has been hypotonia ( $3 / 7$ cases), with tiptoe walking (3/7 cases) and microcephaly (3/7). Verbal skills vary widely from normal to very poor, while motor skills also appear to vary in the number of cases (3/7). Dysmorphic features have in general not been noticed until later in life and are often quite subtle, while some dysmorphic features like clinodactyly, syndactyly (2/7), and hypogonadism (1/7) have been reported infrequently. Both our patient and patient 3 reported by Grisart et al. [17] do not appear to suffer any increased phenotypic severity despite the presence of an additional CNV.

In contrast to the above, the corresponding 17q21.31 microdeletion syndrome is characterised by developmental delay, hypotonia, facial dysmorphisms, and a friendly, amiable behaviour [33-35]. A number of recent reports have shown that loss of function of the KANSL1 gene within this region is sufficient to cause the syndrome $[12,13]$. The 17q21.31 microduplication phenotype appears milder, while some of the more severe congenital malformations seen in the microdeletion syndrome such as urological anomalies, ventriculomegaly, musculoskeletal problems, dental abnormalities, and epilepsy have not been reported in patients with the corresponding microduplication [33-35]. Also of 


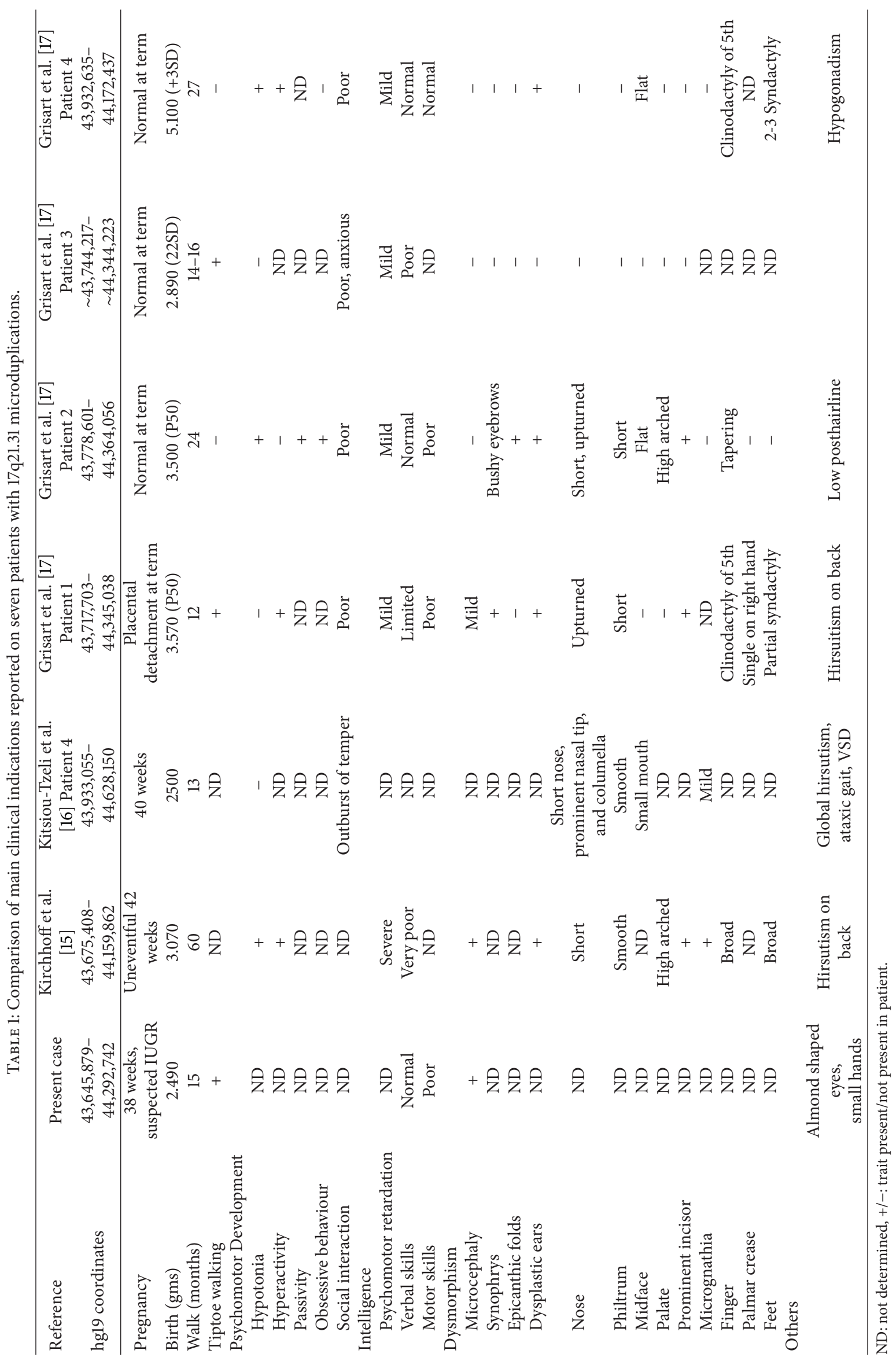


interest is a recent report of a de novo triplication of the MAPT and KANSL1 genes which extends into the polymorphic region of $17 \mathrm{q} 21.31$ [36]. The phenotype of this patient included behavioural and social problems, muscular hypotonia, hypoplastic genitalia, cryptorchidism, clinodactyly, and mild facial dysmorphisms, which is largely similar to the microduplication cases with minor facial features, behavioural problems, and moderate mental impairment.

The extent of the 17q21.32 microduplication among the patients shown in Table 1 varies from approximately $239 \mathrm{~kb}$ to $736 \mathrm{~kb}$. An assessment of published cases and information from the DECIPHER database (http://decipher .sanger.ac.uk/) suggests that none of the cases contained full duplications of all of the main genes contained within the $M A P T$ haplotype. Our patient contained a full copy of MAPT and CRHR1 and a partial copy of KANSL1 genes. Two patients reported by Kitsiou-Tzeli et al. [16] and Grisart et al. [17] (patients 4, Figure 1) appear to be the only cases reported thus far that do not contain a full or partial duplication of CRHR1 gene. Our patient has a similar duplication to that of patient 1 reported by Grisart et al. [17] who has a $646 \mathrm{~kb}$ deletion, but with slightly varying breakpoints and with only a partial duplication of CRHR1. Both phenotypes were similar with common features including tiptoe walking, microcephaly, and poor motor skills. The main difference between these two cases appeared to be hypotonia and more severe dysmorphic features. Patient 4 reported by Grisart et al. [17] carries the smallest microduplication reported so far of $0.24 \mathrm{Mb}$. It contains a full duplication of the MAPT gene and a very small partial duplication of the KANSL1 gene. This patient's phenotype appears to be the mildest of the cases reported with normal verbal and motor skills, psychomotor development and retardation similar to other cases, and mild dysmorphic features. Interestingly, the patient reported by Kirchhoff et al. [15] appears to lack a duplication of the KANSL1 gene but has a full duplication of the MAPT and CRHR1 genes and manifests similar psychomotor development, more severe psychomotor retardation, poorer verbal skills, and microcephaly in comparison to this case. A degree of variable penetrance may exist within the phenotype of the cases reported so far. Therefore while we cannot rule out the contribution of any gene or part of gene in the haplotype to the overall phenotype, patient 4 reported by Grisart et al. [17] may represent the minimum duplication of the $17 \mathrm{q} 21.31$ region that characterises this microduplication syndrome. It is possible that a minimum critical region encompassing the MAPT gene may emerge when further cases become apparent.

The MAPT gene is flanked by LCRs (Figure 1). NAHR involving LCRs can lead to deletion and duplication events, and the complex structure of LCRs that comprise both direct and indirect repeat elements can lead to inversions $[5-8,37]$. While still to be determined for humans, in vivo experiments using mouse cells have shown that a minimum efficient processing segment (MEP) between 134 and 232 bp of perfect shared sequence identity is required for homologous recombination [3]. Koolen et al. [33] have identified an approximate $500 \mathrm{bp}$ within an L2 LINE repetitive element motif at $17 \mathrm{q} 21.31$, representing a possible proximal hotspot for NAHR within this haplotype. The distal breakpoint in the 17q21.31 microdeletion syndrome cases has been determined to be more variable due to it being located in a polymorphic region adjacent to the critical deletion region [33].

Compared to the corresponding microdeletion syndrome, 17q21.31 microduplications have been seen less frequently. A recent study [15] reported the frequency among live births of $1 / 55,000$ and 1/327,000 for microdeletions and microduplications, respectively, which suggests a ratio of $6: 1$, which is lower than expected of NAHR [6]. Importantly, these ratios should be viewed against the molecular background in which they occur and the genomic region being investigated in that the $\mathrm{H} 2$ inversion haplotype is expected to favour microdeletions as opposed to microduplications [11]. The case reported here carries the $\mathrm{H} 2$ haplotype but is associated with a copy number gain rather than loss. Finally, it is possible that cases of $17 q 21.31$ microduplication syndrome have been underascertained due to the milder phenotype and later onset.

\section{Conflict of Interests}

The authors declare that there is no conflict of interests regarding the publication of this paper.

\section{References}

[1] L. Potocki, K.-S. Chen, S.-S. Park et al., "Molecular mechanism for duplication 17p11.2- the homologous recombination reciprocal of the Smith-Magenis microdeletion," Nature Genetics, vol. 24, no. 1, pp. 84-87, 2000.

[2] T. M. Yobb, M. J. Somerville, L. Willatt et al., "Microduplication and triplication of 22q11.2: a highly variable syndrome," The American Journal of Human Genetics, vol. 76, no. 5, pp. 865-876, 2005.

[3] A. S. Waldman and R. M. Liskay, "Dependence of intrachromosomal recombination in mammalian cells on uninterrupted homology," Molecular and Cellular Biology, vol. 8, no. 12, pp. 5350-5357, 1988.

[4] J. A. Bailey, A. M. Yavor, H. F. Massa, B. J. Trask, and E. E. Eichler, "Segmental duplications: organization and impact within the current human genome project assembly," Genome Research, vol. 11, no. 6, pp. 1005-1017, 2001.

[5] J. R. Lupski, "Hotspots of homologous recombination in the human genome: not all homologous sequences are equal," Genome Biology, vol. 5, no. 10, article 242, 2004.

[6] J. R. Lupski and P. Stankiewicz, "Genomic disorders: molecular mechanisms for rearrangements and conveyed phenotypes," PLoS Genetics, vol. 1, no. 6, article e49, 2005.

[7] D. J. Turner, M. Miretti, D. Rajan et al., "Germline rates of de novo meiotic deletions and duplications causing several genomic disorders," Nature Genetics, vol. 40, no. 1, pp. 90-95, 2008.

[8] P. Stankiewicz and J. R. Lupski, "Structural variation in the human genome and its role in disease," Annual Review of Medicine, vol. 61, pp. 437-455, 2010.

[9] H. Stefansson, A. Helgason, G. Thorleifsson et al., "A common inversion under selection in Europeans," Nature Genetics, vol. 37, no. 2, pp. 129-137, 2005. 
[10] P. N. Rao, W. Li, L. E. L. M. Vissers, J. A. Veltman, and R. A. Ophoff, "Recurrent inversion events at 17q21.31 microdeletion locus are linked to the MAPT H2 haplotype," Cytogenetic and Genome Research, vol. 129, no. 4, pp. 275-279, 2010.

[11] M. C. Zody, Z. Jiang, H.-C. Fung et al., "Evolutionary toggling of the MAPT 17q21.31 inversion region," Nature Genetics, vol. 40, no. 9, pp. 1076-1083, 2008.

[12] D. A. Koolen, J. M. Kramer, K. Neveling et al., "Mutations in the chromatin modifier gene KANSL1 cause the 17q21.31 microdeletion syndrome," Nature Genetics, vol. 44, no. 6, pp. 639-641, 2012.

[13] M. Zollino, D. Orteschi, M. Murdolo et al., "Mutations in KANSL1 cause the 17q21.31 microdeletion syndrome phenotype," Nature Genetics, vol. 44, no. 6, pp. 636-638, 2012.

[14] M. Baker, I. Litvan, H. Houlden et al., "Association of an extended haplotype in the tau gene with progressive supranuclear palsy," Human Molecular Genetics, vol. 8, no. 4, pp. 711-715, 1999.

[15] M. Kirchhoff, A.-M. Bisgaard, M. Duno, F. J. Hansen, and M. Schwartz, "A 17q21.31 microduplication, reciprocal to the newly described 17q21.31 microdeletion, in a girl with severe psychomotor developmental delay and dysmorphic craniofacial features," European Journal of Medical Genetics, vol. 50, no. 4, pp. 256-263, 2007.

[16] S. Kitsiou-Tzeli, H. Frysira, K. Giannikou et al., "Microdeletion and microduplication $17 \mathrm{q} 21.31$ plus an additional $\mathrm{CNV}$, in patients with intellectual disability, identified by array-CGH," Gene, vol. 492, no. 1, pp. 319-324, 2012.

[17] B. Grisart, L. Willatt, A. Destrée et al., "17q21.31 microduplication patients are characterised by behavioural problems and poor social interaction," Journal of Medical Genetics, vol. 46, no. 8, pp. 524-530, 2009.

[18] S. W. Scherer, S. Soder, R. M. Duvoisin, J. J. Huizenga, and L.-C. Tsui, "The human metabotropic glutamate receptor 8 (GRM8) gene: a disproportionately large gene located at 7q31.3-q32.1," Genomics, vol. 44, no. 2, pp. 232-236, 1997.

[19] F. J. Serajee, H. Zhong, R. Nabi, and A. H. M. M. Huq, "The metabotropic glutamate receptor 8 gene at 7q31: partial duplication and possible association with autism," Journal of Medical Genetics, vol. 40, no. 4, p. e42, 2003.

[20] J. Elia, J. T. Glessner, K. Wang et al., "Genome-wide copy number variation study associates metabotropic glutamate receptor gene networks with attention deficit hyperactivity disorder," Nature Genetics, vol. 44, no. 1, pp. 78-84, 2011.

[21] A. Delacourte and L. Buee, "Tau pathology: a marker of neurodegenerative disorders," Current Opinion in Neurology, vol. 13, no. 4, pp. 371-376, 2000.

[22] A. M. Pittman, A. J. Myers, P. Abou-Sleiman et al., "Linkage disequilibrium fine mapping and haplotype association analysis of the tau gene in progressive supranuclear palsy and corticobasal degeneration," Journal of Medical Genetics, vol. 42, no. 11, pp. 837-846, 2005.

[23] A. B. Singleton, M. Farrer, J. Johnson et al., " $\alpha$-Synuclein locus triplication causes Parkinson's disease," Science, vol. 302, no. 5646, p. 841, 2003.

[24] A. Rovelet-Lecrux, D. Hannequin, G. Raux et al., "APP locus duplication causes autosomal dominant early-onset Alzheimer disease with cerebral amyloid angiopathy," Nature Genetics, vol. 38, no. 1, pp. 24-26, 2006.

[25] S. J. Adams, R. J. P. Crook, M. DeTure et al., "Overexpression of wild-type murine tau results in progressive tauopathy and neurodegeneration," The American Journal of Pathology, vol. 175, no. 4, pp. 1598-1609, 2009.

[26] A. Lladó, B. Rodríguez-Santiago, A. Antonell et al., "MAPT gene duplications are not a cause of frontotemporal lobar degeneration," Neuroscience Letters, vol. 424, no. 1, pp. 61-65, 2007.

[27] E. B. De Souza, "Corticotropin-releasing factor receptors: physiology, pharmacology, biochemistry and role in central nervous system and immune disorders," Psychoneuroendocrinology, vol. 20, no. 8, pp. 789-819, 1995.

[28] Y. Ishitobi, S. Nakayama, K. Yamaguchi et al., "Association of CRHR1 and CRHR2 with major depressive disorder and panic disorder in a Japanese population," The American Journal of Medical Genetics B, vol. 159, no. 4, pp. 429-436, 2012.

[29] F. Van Den Eede, T. Venken, J. Del-Favero et al., "Single nucleotide polymorphism analysis of corticotropin-releasing factor-binding protein gene in recurrent major depressive disorder," Psychiatry Research, vol. 153, no. 1, pp. 17-25, 2007.

[30] E. Erez, D. Fass, and E. Bibi, "How intramembrane proteases bury hydrolytic reactions in the membrane," Nature, vol. 459, no. 7245, pp. 371-378, 2009.

[31] E. R. Smith, C. Cayrou, R. Huang, W. S. Lane, J. Côté, and J. C. Lucchesi, "A human protein complex homologous to the Drosophila MSL complex is responsible for the majority of histone H4 acetylation at lysine 16," Molecular and Cellular Biology, vol. 25, no. 21, pp. 9175-9188, 2005.

[32] C. Conrad, C. Vianna, M. Freeman, and P. Davies, "A polymorphic gene nested within an intron of the tau gene: implications for Alzheimer's disease," Proceedings of the National Academy of Sciences of the United States of America, vol. 99, no. 11, pp. 77517756, 2002.

[33] D. A. Koolen, A. J. Sharp, J. A. Hurst et al., "Clinical and molecular delineation of the 17q21.31 microdeletion syndrome," Journal of Medical Genetics, vol. 45, no. 11, pp. 710-720, 2008.

[34] C. Shaw-Smith, A. M. Pittman, L. Willatt et al., "Microdeletion encompassing MAPT at chromosome $17 \mathrm{q} 21.3$ is associated with developmental delay and learning disability," Nature Genetics, vol. 38, no. 9, pp. 1032-1037, 2006.

[35] T. Y. Tan, S. Aftimos, L. Worgan et al., "Phenotypic expansion and further characterisation of the $17 \mathrm{q} 21.31$ microdeletion syndrome," Journal of Medical Genetics, vol. 46, no. 7, pp. 480489, 2009.

[36] A. Gregor, M. Krumbiegel, C. Kraus, A. Reis, and C. Zweier, “De novo triplication of the MAPT gene from the recurrent $17 \mathrm{q} 21$. 31 microdeletion region in a patient with moderate intellectual disability and various minor anomalies," American Journal of $J$ Medical Genetics A, vol. 158, no. 7, pp. 1765-1770, 2012.

[37] O. A. Shchelochkov, S. W. Cheung, and J. R. Lupski, "Genomic and clinical characteristics of microduplications in chromosome 17," The American Journal of Medical Genetics A, vol. 152, no. 5, pp. 1101-1110, 2010. 


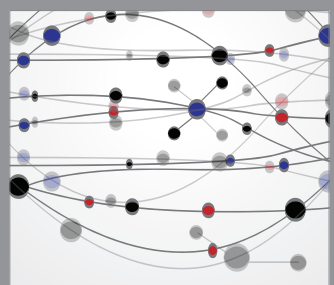

The Scientific World Journal
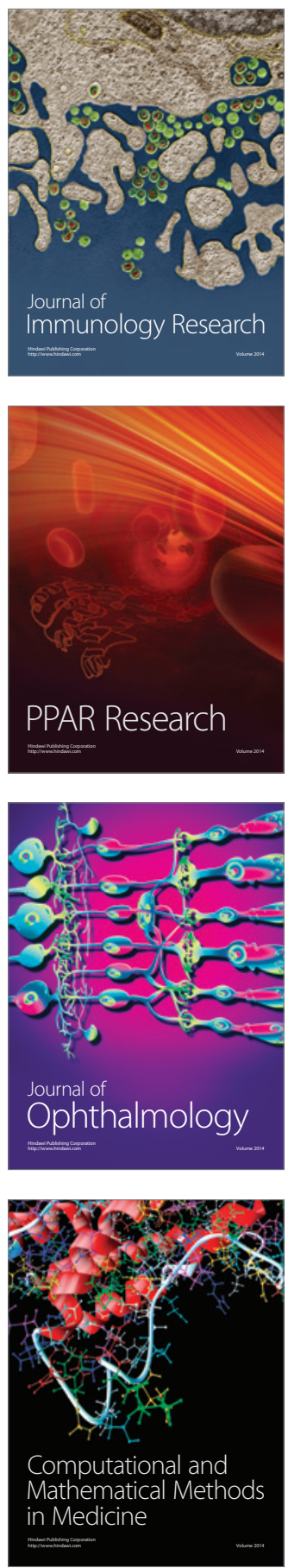

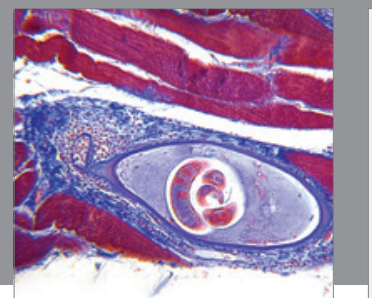

Gastroenterology

Research and Practice
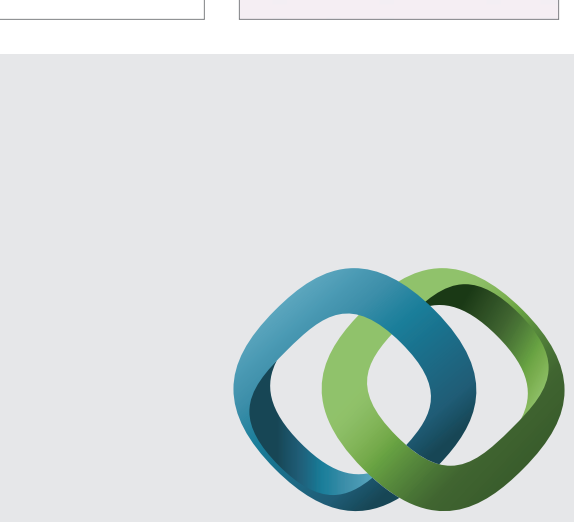

\section{Hindawi}

Submit your manuscripts at

http://www.hindawi.com
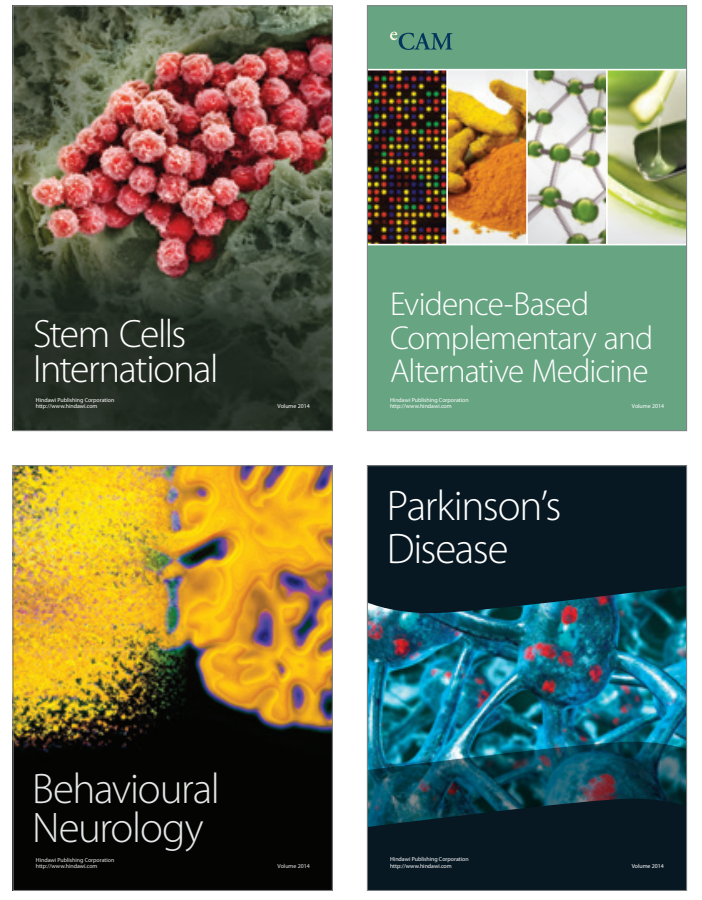
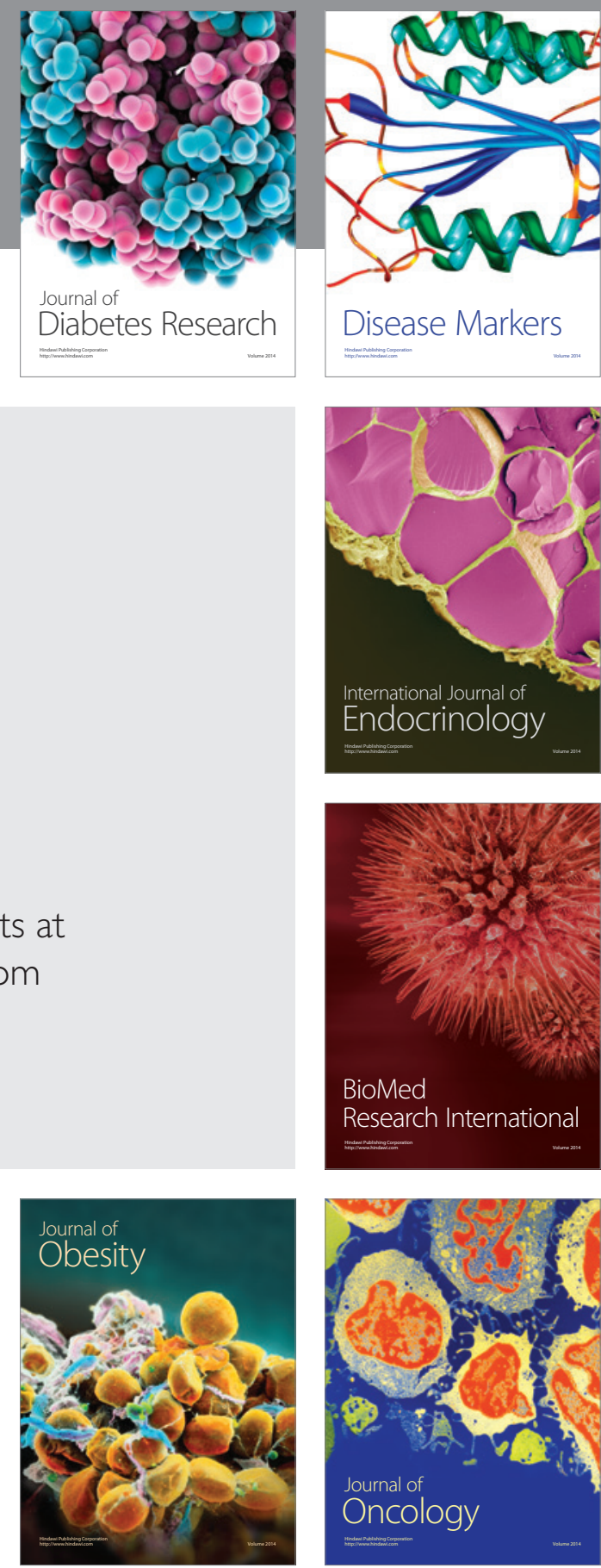

Disease Markers
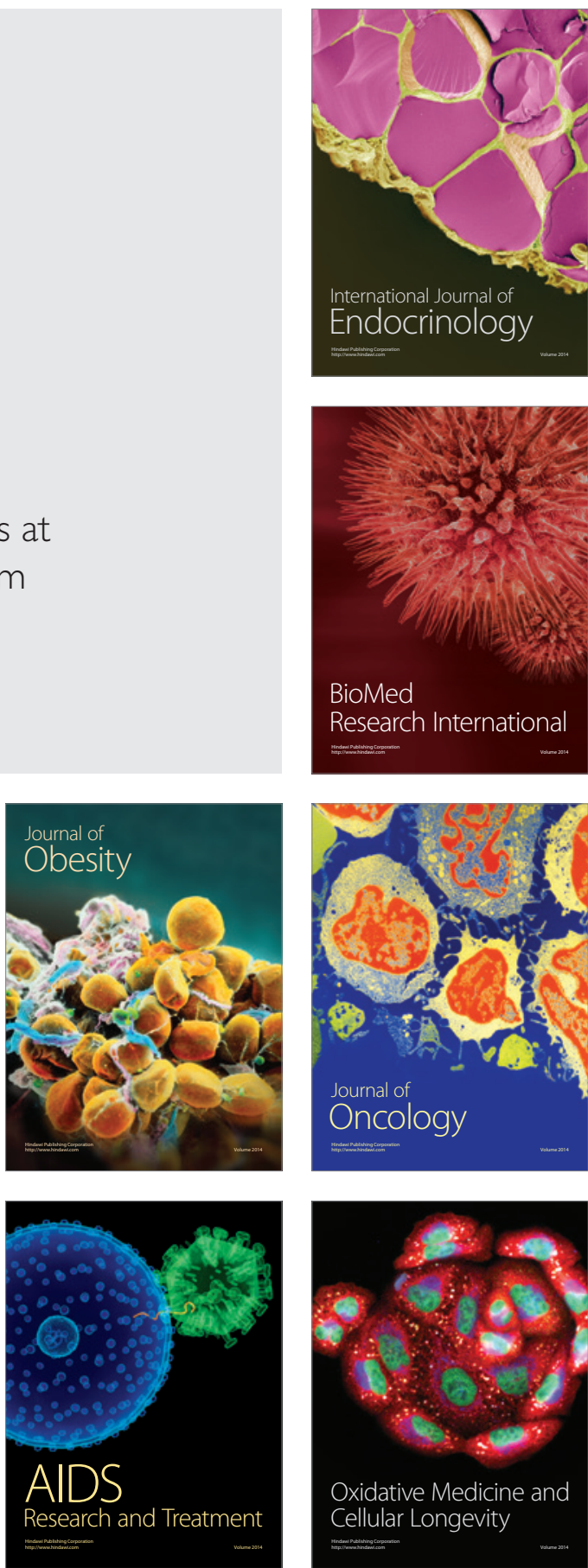